\title{
NUTRITION AND HEALTH STATUS ASSESSMENT OF GERIATRIG PEOPLE OF ONE RURAL DISTRICT IN NEPAL
}

\author{
Shrestha $L^{1}$, Bastola $P^{2}$
}

${ }^{1}$ Department of Community Medicine, Nepalese Army Institute of Health Science, Kathmandu, and Health Home Care

Nepal (Elderly Care Home), Lalitpur, ${ }^{2}$ Shree Birendra Hospital , Chhauni, Kathmandu, Nepal

\begin{abstract}
Aging is an inevitable process, old age cannot be healed. It can only be protected, promoted and extended by adding quality to life. To explore the health and nutrition status of geriatric people that need to be accommodated in future priority health programme of Nepal this cross sectional study was done in two selected rural VDCs of Rupandehi District of Nepal. In this study out of a total of participants $(n=364) 9.0 \%$ were severely underweight, $15.5 \%$ were underweight and $24.5 \%$ were malnourished. Three hundred and sixteen (85.9\%) participants had health problems, which were mainly respiratory diseases, hypertension and diabetes mellitus. Among the participants, $22.3 \%$ had problem for activities of daily living (AODL) and $50.8 \%$ had cognitive impairment. The nutritional status appeared to decline with advancing age and both the genders were equally susceptible to malnutrition. Nutritional status of elderly was not found to be associated with health problems, alcohol intake, literacy and cognitive impairment, whereas it was found to be associated with smoking and compromised daily activities. The findings of this study help to fill the gap in health and nutritional measures that address the needs of this group of people in Nepal.
\end{abstract}

\section{KEYWORDS}

Elderly people, health status, nutritional status

\section{CORRESPONDING AUTHOR}

Prof. Dr. Lochana Shrestha, MBBS, MD

Head of Department of Community Medicine,

Nepalese Army Institute of Health Science,

Kathmandu, Nepal,

Email: lochanashrestha@gmail.com 


\section{INTRODUCTION}

In recent years, there has been a sharp increase in the number of old people worldwide, mostly as a consequence of declining fertility, improved health care facilities and reduced mortality rates in later life. Globally the proportion of elderly, defined as aged 60 years or over, has risen from $8 \%$ in 1950 to $11 \%$ in 2007 , and is expected to reach $22 \%$ in 2050. By 2025, the number of elderly worldwide is expected to reach more than 1.2 billion, with about 840 million of these in low-income countries..$^{1,2}$ Rapid demographic aging is a growing public health issue in many low- and middle-income countries (LAMICs). According to the 2011 census, conducted by the Central Bureau of Statistics of Nepal, the population of people aged 60 years and above, called senior citizens was 2.15 million, accounting for 8,1 percent of Nepal's total population of 26.5 million.

Geriatric population forms a significant proportion of our total population and this group of people is vulnerable to multiple physical, mental and social problems. Hence, various factors affecting the overall health of the elderly need special consideration. Nutrition is an important determinant of health across all ages including aging group. Nutritional status has increasingly been associated with a variety of morbid conditions including cancer, heart disease and dementia among in persons over the age of 65 . The overwhelming health problems among this group of people will need to be tackled by concerned individuals, communities and governments. Programmes should be designed and implemented specifically to meet the needs of these people, to address the factors that bring detrimental impact in health of elderly people and to improve their health status. Because of limited information about nutrition and health status in this group in Nepal, programmes are lacking to address the problem in this group.

With this background, to explore the association of health (physical and cognitive) and nutritional status of elderly people this study was carried out. The findings might help to fill the gap in health measures that address the needs of this group of people in Nepal.

\section{MATERIALS AND METHODS}

Study population: Elderly people above 65 years who were not ill and bed ridden

Study design: A Community based Cross Sectional study

Study Place: Two VDCs (Bhagawanpur and Ekala) of Rupandehi Dstrict, Lumbini

Sample size: The respondents above 65 years old people were selected according to proportionate sampling technique and first respondent from each ward was selected with pen drop sampling method and then snow ball sampling technique was used.
The sample size was 380 in order to allow estimation of a typical dementia prevalence of $4.5 \%$ (SE 0.9\%) with $80 \%$ power. Here prevalence of dementia is used from India. $^{3}$ All community-resident individuals aged 65+ years that were not ill and bed ridden were eligible for inclusion. Using a process of full household enumeration, all residents aged 65+ years within catchment areas were approached by means of door-knocking and a reliable informant was required for inclusion. Being younger than 65 years was the only exclusion criteria, and weighted sampling procedures were not applied.

Study period: This study was done within a period of six months (November 2017 to April 2018).

\section{Data Collection:}

Data was collected by trained interviewers by face to face interview technique with the preparation of interview schedule and necessary pretesting.

Standardized assessments of physical health, and cognitive function were carried out with standardized interview tool. ${ }^{3}$

Nutritional status assessed with anthropometric measurements of height using measurement tape and weight using adult weighing machine and calculated body mass index (BMI).

\section{Data Analysis:}

Collected data analyzed through SPSS version 16 . Data analyses were done with chi-square test.

\section{Data collection tools:}

Questionnaire for interview (Quantitative) and monitoring supervision checklist

\section{Ethics Statement:}

Written informed consent, or witnessed oral consent in case of illiteracy, or next of kin written agreement in case of difficulty in understanding/speak was obtained from all participants.

Ethical approval for this study was taken from Institutional review committee of Nepalese Army Institute of Health Science.

\section{RESULTS}

Among 380 sample participants, information from 364 participants was included for analysis as the remaining didn't give complete information. Among the study population, majority were males 233 (64.4\%) and 129 (35.6\%) were females; majority (73\%) were in young old age group (64-74) years and $5.5 \%$ oldest old group (75-84) years. Majority (79\%) were farmers in past, maximum (65.9\%) didn't have formal education, $76.6 \%$ were from joint family and $92.5 \%$ were living with children as shown in Table 1. In the present study, out of a total of 364 participants 33 (9.0\%) were severely underweight, $57(15.5 \%)$ were underweight while 51 (13.9\%) were overweight and $20(5.4 \%)$ were obese as depicted 
in table $2.8 \quad 85.9 \%$ had health problems, mainly of respiratory, hypertension and diabetes mellitus. Among the participants, $22.3 \%$ had problem for daily activities (AODL) and $50.8 \%$ had cognitive impairment, mainly of subjective memory.

The nutritional status of elderly assessed in relation to their age as shown in table 3 depicts that nutritional status declined as the age advanced, however this was not found to be statistically significant $\left(\chi^{2}=12.008\right.$, P value 0.445$)$. The assessment of nutritional status of elderly in relation to gender

\begin{tabular}{|c|c|c|}
\hline Characteristics & $n=364$ & $\%$ \\
\hline \multicolumn{3}{|l|}{ Age group } \\
\hline$<64$ years & 15 & 4.1 \\
\hline Young old (64-74) & 265 & 73 \\
\hline Old old (75-84) & 63 & 17.4 \\
\hline Oldest old (85 and above) & 20 & 5.5 \\
\hline \multicolumn{3}{|l|}{ Sex } \\
\hline Male & 233 & 64.4 \\
\hline Female & 129 & 35.6 \\
\hline \multicolumn{3}{|l|}{ Ethnicity } \\
\hline Brahmin & 135 & 37.5 \\
\hline Chhetry & 49 & 13.6 \\
\hline Newar & 13 & 3.6 \\
\hline Others & 53 & 14.7 \\
\hline Tharu & 101 & 28.1 \\
\hline Dalit & 9 & 2.5 \\
\hline \multicolumn{3}{|l|}{ Past Occupation } \\
\hline Farmer & 286 & 79 \\
\hline Business & 32 & 8.8 \\
\hline Service (Govt.) & 24 & 6.6 \\
\hline Service (Pvt.) & 10 & 2.8 \\
\hline Others & 10 & 2.8 \\
\hline \multicolumn{3}{|l|}{ Educational status } \\
\hline No formal education & 240 & 65.9 \\
\hline Primary education & 81 & 22.3 \\
\hline Secondary education & 34 & 9.3 \\
\hline Tertiary education & 9 & 2.5 \\
\hline \multicolumn{3}{|l|}{ Family } \\
\hline Nuclear & 64 & 17.6 \\
\hline Joint & 278 & 76.6 \\
\hline Extended & 21 & 5.8 \\
\hline \multicolumn{3}{|l|}{ Staying with children } \\
\hline With children & 337 & 92.50 \\
\hline Without children & 27 & 7.50 \\
\hline
\end{tabular}

as shown in table 4 showed no statistically significant difference $\left(\chi^{2}=4.05\right.$, $P$ value 0.398$)$. The nutritional status of elderly in relation to literacy was not statistically significant $\left(\chi^{2}=7.15, \mathrm{P}\right.$ value 0.848$)$ as shown in table 5 . In the present study nutritional status assessment of elderly population in relation to health problems is tabulated in table 6 . It is seen that majority of the malnourished (underweight and severely underweight) had no health problems. No statistically significant difference (Chi square value - 8.069; df-4; P value= 0.089) was observed between the groups.

Table 2: Distribution of different parameters of Participants

\begin{tabular}{lcc|} 
Parameters & $\mathbf{n}$ & $\%$ \\
\multicolumn{2}{l}{ Nutritional status as assessed by BMI $(B M I<16.0$} \\
$\mathrm{kg} / \mathrm{m}^{2}$, Severely Underweight $;$ BMI $<22.0$ & $\mathrm{~kg} / \mathrm{m}^{2}$, \\
underweight; BMI $>27.0$ & $\mathrm{~kg} / \mathrm{m}^{2}$, overweight). \\
Severely & & \\
Underweight & 33 & 9.0 \\
Underweight & 57 & 15.5 \\
Normal & 197 & 53.5 \\
Overweight & 51 & 13.9 \\
Obese & 20 & 5.4 \\
Health problems (self reported) & \\
Absence & 52 & 14.1 \\
presence & 316 & 85.9 \\
Difficulty in Daily activities(AODL) & \\
No & 275 & 74.7 \\
Yes & 82 & 22.3 \\
Cognitive Problem (Selective memory & \\
impairment) & \\
No & 176 & 47.8 \\
Yes & 187 & 50.8 \\
\hline
\end{tabular}

Among the 364 study participants, most 286 (79.8\%) did not consume alcohol and also majority 218 (60.8\%) did not smoke. (Table 7 and 8 ) On assessing the nutritional status of elderly in relation to alcohol intake and smoking, statistically significant difference $\left(\chi^{2}=2.3 ; \mathrm{df}-4\right.$; P value $\left.=0.681\right)$ was not found for nutritional status with respect to alcohol intake whereas statistically significant difference $\left(\chi^{2}=32.87\right.$; df-4; $P$ value $=0.000$ ) was found for nutritional status with respect to smoking habit. (Fig. 1 and 2)

The assessment of nutritional status of elderly in relation to daily living activities (AODL) as shown in Table 7 showed a statistically significant difference $\left(\chi^{2}=28.43 ; \mathrm{df}-4 ; \mathrm{P}\right.$ value $\left.=0.000\right)$ where maximum malnourished (underweight $(26.4 \%)$ and severely underweight (16.9\%) elderly people have difficulty for daily activities. Whereas association between nutritional status and cognitive impairment was found not to be statistically significant (Table 8) which suggests that nutritional level did not influence the cognitive status of elderly people. 
There is not enough evidence to reject the null hypothesis.

\begin{tabular}{|c|c|c|c|c|c|c|}
\hline \multirow{2}{*}{$\begin{array}{l}\text { Age group } \\
\text { Category }\end{array}$} & \multicolumn{6}{|c|}{ Nutritional Status } \\
\hline & $\begin{array}{c}\text { Severely Underweight } \\
(\%)\end{array}$ & Underweight\% & Normal\% & Overweight\% & Obese $\%$ & Total \\
\hline$<64$ years & $2(13.3)$ & $1(6.6)$ & $9(60)$ & $3(20)$ & 0 & 15 \\
\hline Young old (64-74) & $21(8.0)$ & $44(16.8)$ & $137(52.4)$ & $41(15.7)$ & $18(6.8)$ & 261 \\
\hline Old old (75-84) & $6(9.8)$ & $8(13.1)$ & $39(63.9)$ & $6(9.8)$ & $2(3.2)$ & 61 \\
\hline $\begin{array}{l}\text { Oldest old ( } 85 \\
\text { and above) }\end{array}$ & $4(20.0)$ & $4(20.0)$ & $11(55.0)$ & $1(5.0)$ & 0 & 20 \\
\hline Total & 33 & 57 & 196 & 51 & 20 & 357 \\
\hline
\end{tabular}

\begin{tabular}{|lcccccc|}
\hline \multicolumn{7}{c|}{ Table 4: Distribution of nutritional status in relation to gender } \\
\hline Gender & \multicolumn{7}{c|}{ Nutritional Status } \\
Category & Severely Underweight & Underweight & Normal & Overweight & Obese & Total \\
Male & 18 & 37 & 125 & 38 & 11 & 229 \\
Female & 15 & 20 & 71 & 13 & 8 & 127 \\
Total & 33 & 57 & 196 & 51 & 19 & 356 \\
Chi square value -4.057 ; df-4; P value= $=.398$ & & & & \\
\hline
\end{tabular}

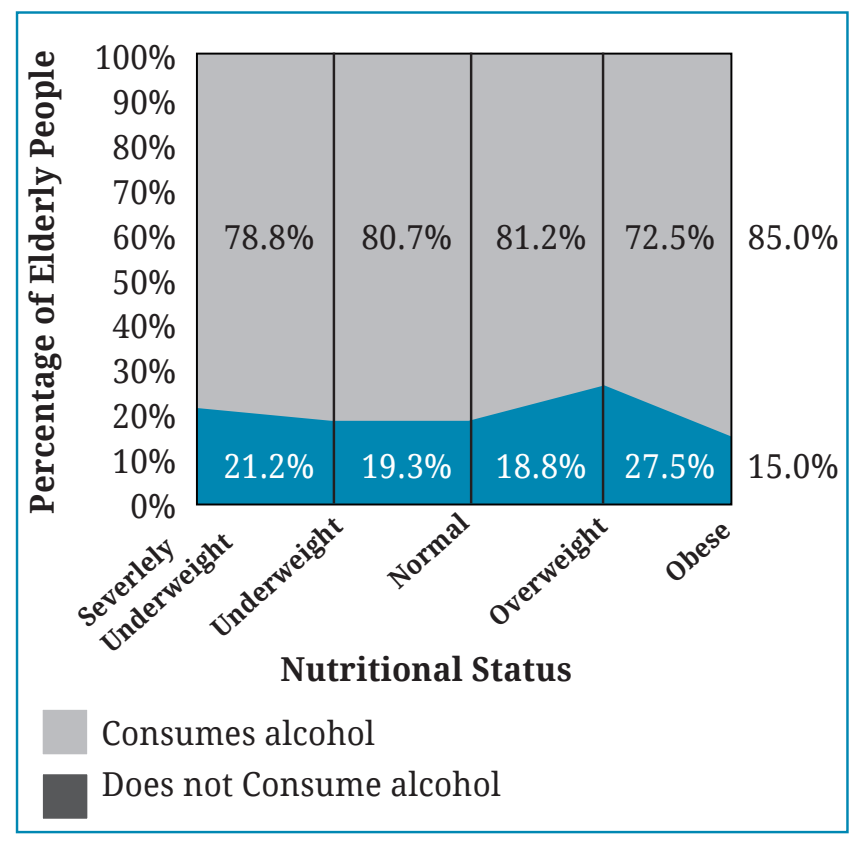

Fig. 1: Distribution of nutritional status in relation to alcohol intake $(\mathrm{P}$ value $=0.681)$

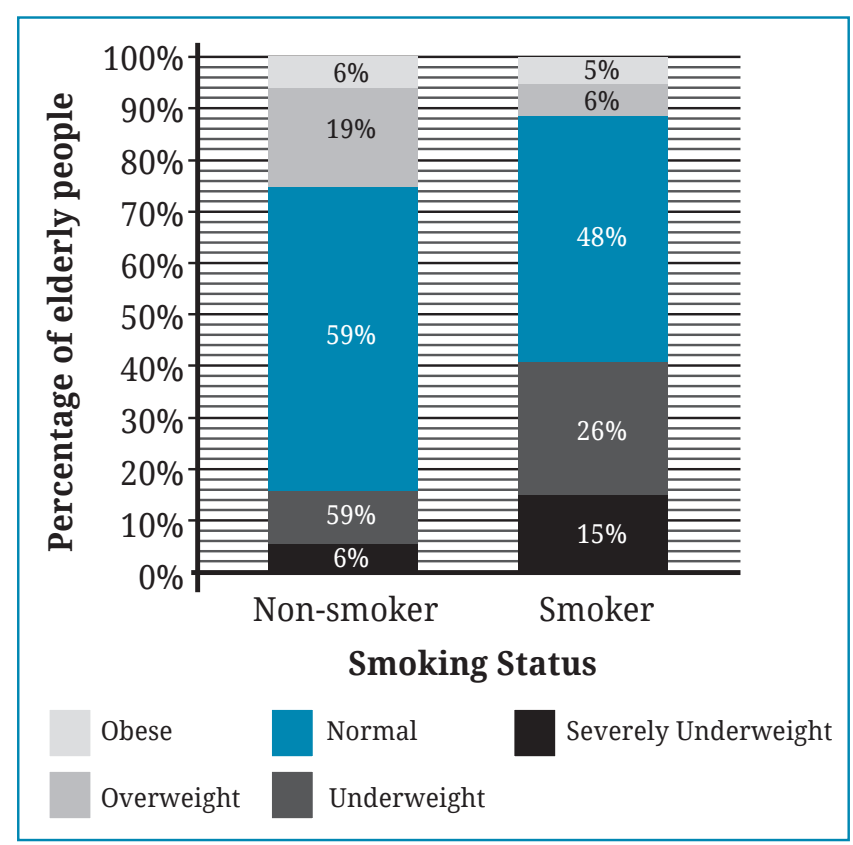

Fig. 2: Distribution of nutritional status in relation to smoking $(\mathrm{P}$ value $=0.000)$

\begin{tabular}{|lcccccc|}
\hline \multicolumn{7}{c}{ Table 5: Distribution of nutritional status in relation to literacy } \\
Literacy & Nutritional status \\
Category & Severely Underweight & Underweight & Normal & Overweight & Obese & Total \\
No formal education & 23 & 40 & 132 & 30 & 11 & 236 \\
Primary education & 6 & 13 & 44 & 11 & 6 & 80 \\
Secondary education & 3 & 3 & 16 & 8 & 3 & 33 \\
Tertiary education & 1 & 1 & 5 & 2 & 0 & 9 \\
Total & 33 & 57 & 197 & 51 & 20 & 358 \\
(P value= 0.848) & & & & & & \\
\hline
\end{tabular}


Table 6: Distribution of nutritional status in relation to health problems

\section{Health problems}

Category

Without health

problem

With health problem

Total

\section{Nutritional Status}

\begin{tabular}{cccccc} 
Severely Underweight & Underweight & Normal & Overweight & Obese & Total \\
$6(12.8 \%)$ & $11(23.4 \%)$ & $27(57.4 \%)$ & $3(6.4 \%)$ & $0(0.0 \%)$ & 47 \\
$27(8.7 \%)$ & $46(14.8 \%)$ & $170(54.7 \%)$ & $48(15.4 \%)$ & $20(6.4 \%)$ & 311 \\
$33(9.2 \%)$ & $57(15.9 \%)$ & $197(55.0 \%)$ & $51(14.2 \%)$ & $20(5.6 \%)$ & 358 \\
\hline
\end{tabular}

\section{Table 7: Distribution of nutritional status in relation to difficulty in AODL}

Difficulty in AODL
Category
No
Yes

Total

*AODL= Activities of daily living

Chi square value $-28.43 ; \mathrm{df}-4 ; \mathrm{P}$ value $=0.000$

\section{Nutritional Status}

$\begin{array}{cccccc}\text { Severely Underweight } & \text { Underweight } & \text { Normal } & \text { Overweight } & \text { Obese } & \text { Total } \\ 15(6.1 . \%) & 30(12.1 . \%) & 144(58.3 . \%) & 39(15.8 \%) & 19(7.7 \%) & 247 \\ 18(16.9 \%) & 28(26.4 \%) & 48(45.3 . \%) & 11(10.3 \%) & 1(0.9 \%) & 106 \\ 33(9.3 . \%) & 58(16.4 \%) & 192(54.5 . \%) & 50(14.2 \%) & 20(5.6 \%) & 353\end{array}$

Table 8: Distribution of nutritional status in relation to Cognitive impact

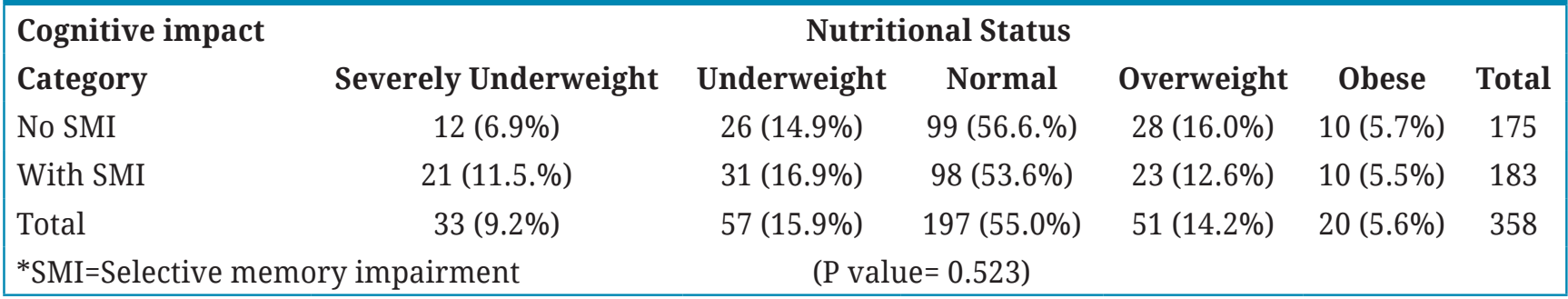

\section{DISCUSSION}

Aging is an inevitable process, old age cannot be healed. It can only be protected, promoted and extended by adding quality to life.

In the present study out of a total 364 participants $33(9.0 \%)$ were severely underweight, $57(15.5 \%)$ were underweight. That means $24.7 \%$ were malnourished. This finding was similar as in study done by Ghimire S team in Nuwakot, ${ }^{8}$ whereas study done by Singh in old age homes of Kathmandu showed only $15.5 \%$ malnourished elderly people, ${ }^{9}$ and study done by Lyons in Pharping showed $31 \%{ }^{10}$ Study done in Bangladesh in 2015 showed $50 \%$ chronic energy malnutrition among elderly people. ${ }^{11}$ In study conducted in Iran by Aliabadi M et al showed $12.0 \%$ malnourished out of total elderly population of $1962 .{ }^{12}$ Similar institution based study also indicates that the prevalence of malnutrition ranges from $5-10 \%$ in free-living elderly to $30-85 \%$ in homebound, nursing home, and hospitalized elderly.13,14 Whereas study done by Crogan NL15 showed 38.6\% malnourished.

There are many factors which determine the nutritional status of elderly people evidenced with aging. ${ }^{16,17}$ In the present study the nutritional status declines with the advancing age and both the genders are equally susceptible to malnutrition. In addition nutritional status of elderly is not found to be associated with health problems, alcohol intake, literacy and cognitive impairment, whereas found to be associated with smoking, ${ }^{18,19}$ and daily activities, which shows that smoking needs to control to maintain good nutritional status among elderly and also for maintain daily activities by own self maintenance of good nutritional status is very important. However Boscatto et al, study presents more malnourishment among respondents who had negative physical health conditions such as suffering from hypertension (18.8\%) and diabetes (19\%).

Geriatric nutritional assessment should be integrated into a comprehensive geriatric assessment. The social security scheme meant for the elderly needs to be more effectively implemented at the community level which in turn can influence their nutritional status and health outcomes. Assessment of the nutritional status regularly followed by early interventions will improve the health outcomes, prevents the onset of disability, improves quality of life and saves healthcare costs.

Early identification of the nutritional status would help to implement required interventions on time 
which will help to prevent different morbidity conditions due to poor nutritional status. This in turn will bring overall healthy elderly population in future.

\section{REFERENCES}

1. Global Health and Aging, WHO 2011.

2. Tuladhar J et al. Nutritional Needs of Older People in Tansen Palpa, Nepal. Int'l J Pharmaceutical Biol Arch 2013; 4: 951-5.

3. Sosa AL, Albanese E, Stephan BCM, Dewey M, Acosta D, Ferri CP et al. (2012) Prevalence, Distribution, and Impact of Mild Cognitive Impairment in Latin America, China, and India: A 10/66 PopulationBased Study. PLoS Med 9: e1001170. https://doi. org/10.1371/journal.pmed.1001170

4. Central Bureau of Statistics. Population census 2011, National Report. Kathmandu: His Majesty's Government National Planning Commission Secretariat, 2012.

5. Shrestha L. Geriatric Health in Nepal: Concerns and Experience. Nepal Med Col J 2012; 15: 144-148.

6. Ageing and health in Nepal. Regional Health Forum WHO South East Asia region 2012; 16: 12-16.

7. Aging and nutrition: a growing global challenge, nutrition for older persons WHO 2012 website: www.who.int.

8. Ghimire S, Baral BK, Callahan K. Nutritional assessment of community-dwelling older adults in rural Nepal. PLOS One 2017; 12: e0172052.

9. Singh DR, Shrestha S. Nutritional status of senior citizens living in old age homes of Kathmandu metropolitan municipality. Int J Community Med Public Health 2016; 3: 1707-15.

10. Lyons G. Malnutrition: Elderly People in Nepal: Research Briefing Note. Kathmandu: Ageing Nepal University of Sheffield, 2012.

11. Kabir ZN, Ferdous T, Cederholm T, Khanam MA.
Mini Nutritional Assessment of rural elderly people in Bangladesh: the impact of demographic, socio-economic and health factors. Public Health Nutr 2006; 9: 968-74.

12. Aliabadi M, Kimiagar M, Ghayour MM. Prevalence of malnutrition in free living elderly people in Iran: a cross-sectional study. Asia Pacific J Clinic Nutr 2008; 17: 285-9

13. Bradshow SN, Playford ED, Riazi A. Living well in care homes: a systematic review of qualitative studies. Age Ageing 2012; 41: 429-40.

14. Guigoz Y, Vellas BJ. Malnutrition in elderly: The Mini Nutritional Assessment. Ther Umsch 1997; 54: 345-50.

15. Crogan NL \& Pasvogel A. The influence of proteincalorie malnutrition on quality of life in nursing homes. J Gerontol A Bio Sci Med Sci 2003; 58: 159164.

16. Anderson I, Petterson E, Sidenval B. Daily Life after moving inta a care home experience from older people, realitives and contact persons. J Clinic Nurs 2007; 16: 1712-8.

17. Chang SJ. Lived experience of nursing home resident in Korea. Asian Nurs Resc 2013; 7: 83-90.

18. Boscatto EC, Duarte MF, Cocqueiro RS, Barbosa AR. Nutritional status in the oldest elderly and associated factors. Rev Assoc Med Bras 2013; 1: 407.

19. Faraes D, Barbosa AR, Borgatto AF, Coquetro RS, Fernandess MH. Factors associated with nutritional status of the elderly in two regions of Brazil. Rev Assoc Med Bras 2012; 58: 434-41. 